\title{
STUDI PERATURAN MAHAR DI PAKISTAN: TELAAH ARGUMENTASI DAN TUJUAN PEMBENTUKAN
}

\author{
Mohammad Fauzan Ni'ami \\ UIN Sunan Kalijaga Yogyakarta \\ Email: niamifauzan01@gmail.com
}

\begin{abstract}
Abstrak
Tulisan ini mengupas tentang dasar argumentasi dan tujuan pembentukan peraturan UU Mahar 1976 di Pakistan. Didahului dengan pembahasan konsep mahar dan struktur sosial pakistan, argumentasi adanya peraturan mahar, serta tujuan peraturan mahar di Pakistan. Metode yang dipakai adalah deskripsi kualitatif dengan pendekatan fakta teoritis melalui media informasi baik berita, artikel, dan sumber lainya. Hasil penelitian ini menunjukan dasar argumentasi pembentukan aturan mahar di Pakistan adalah perbedaan pemahaman konsep mahar dan praktek mahar menimbulkan problem sosial. Sedangkan tujuan aturan mahar ini yaitu a). Untuk memberikan kepastian hukum, berkenaan dengan masalah perkawinan, khususnya mahar. b). Aturan mahar juga merupakan wujud penghargaan bagi kaum perempuan yang hak-haknya dirampas akibat tradisi mahar yang tidak sehat. c). Aturan mahar dinilai dalam rangka menyesuaikan dengan konteks perkembangan zaman, yaitu tuntutan egaliter.
\end{abstract}

Kata Kunci: Mahar, Pakistan, Argumentasi

\begin{abstract}
This paper examines the basic arguments and objectives for the establishment of dowry and bridal gifts act 1976 in Pakistan. It was preceded by a discussion of the concept of dowry and the social structure of Pakistan, arguments for the existence of a dowry regulation, and the purpose of the dowry regulation in Pakistan. The method used is a qualitative description with a theoretical fact approach through information media, both news, articles, and other sources. The results of this study indicate that the basic argument for the formation of dowry rules in Pakistan is the difference in understanding the concept of dowry and the practice of dowry causing social problems. While the purpose of this dowry rule is a). To provide legal certainty, with regard to marital issues, especially dowry. $b$ ). The dowry regulation is also a form of appreciation for women whose rights have been deprived of due to unhealthy dowry traditions. c). The dowry rules are assessed in order to adapt to the context of the times, namely egalitarian demands.
\end{abstract}

Keywords: Dowry, Pakistan, Argumentation 


\section{A. Pendahuluan}

Salah satu hikmah adanya mahar yaitu sebagai upaya perlindungan dan penghormatan kepada kaum perempuan, karena secara filosofi mahar merupakan bukti keseriusan mempelai laki kepada mempelai perempuan. Tidak hanya itu saja, mahar juga mencerminkan nilai kasih yang aktual, pembenaran rasa sayang kepada calon isteri. Khoiruddin Nasution memberikan penafsiran bahwasanya mahar merupakan pemberian suka rela tanpa pamrih sebagai simbol kasih sayang dan cinta dari calon suami terhadap calon isterinya. ${ }^{1}$

Pada awal abad ke-20 berbagai negara Muslim memulai reformasi di bidang hukum keluarga. Salah satu muatan pembaharuan hukum keluarga yaitu mengenai ketentuan mahar pernikahan, hal ini dianggap penting karena sebagai upaya untuk menjaga hak-hak perempuan. Terdapat negara-negara Muslim seperti Kuwait, Indonesia, Mesir, Maroko, dan Pakistan yang secara rinci melegislasi mahar yang diberlakukan di negara tersebut. ${ }^{2}$ Hanya saja negara Pakistan secara jelas membahas besaran mahar yang tertera dalam pasal 3 ayat 1 The Dowry and Bridal Gifts (Restriction) Act 1976 (selanjutnya menjadi UU Mahar 1976) menjelaskanbahwa jumlah mahar maksimal adalah 5000 Rs. $^{3}$ Berbeda dengan negara Indonesia yang menggunakan asas kesederhanaan dan kemudahan tanpa dibatasi jumlah dalam memberikan mahar. ${ }^{4}$

\footnotetext{
${ }^{1}$ Khoiruddin Nasution, Islam Tentang Relasi Suami dan Isti (Hukum Perkawinan 1), Cet I (Yogyakarta: ACAdeMIA \& TAZZAFA, 2004), . 168

${ }^{2}$ Qodariah Barkah, "Kedudukan dan Jumlah Mahar Di Negara Muslim”, Jurnal Ahkam, Vol. XIV, No. 2, (Juli, 2014), 279

3 The Dowry And Bridal Gift (Restriction) Act, 1976 No. 3 ayat 1

${ }^{4}$ Kompilasi Hukum Islam, Pasal 31
}

Sama halnya dengan negara Maroko yang tidak menetapkan besaran mahar, ${ }^{5}$ begitu juga negara Kuwait yang tidak menetapkan batas minimal maupun maksimal dalam mahar. $^{6}$

\section{Pada pasal 2 UU Mahar 1976} menjelaskan perbedaan definitif antara kado pengantin dan mahar (mas kawin). Definisi kado pengantin dalam peraturan tersebut adalah segala harta benda yang diberikan sebagai hadiah sebelum/saat/setelah perkawinan, baik secara langsung, oleh mempelai laki-laki atau orang tuanya kepada mempelai perempuan sehubungan dengan perkawinan tersebut tetapi tidak termasuk mahar. ${ }^{7}$ Sedangkan mahar merupakan segala harta benda yang diberikan kepada mempelai wanita, sebelum/saat/setelah pernikahan baik secara langsung maupun tidak langsung, tetapi bukan termasuk harta yang bisa diwarisi oleh mempelai perempuan berdasarkan hukum waris. ${ }^{8}$

Hal demikian penting dijelaskan mengingat salah satu faktor munculnya peraturan tersebut adalah karena kerancuan dalam memahami mahar dan hadiah, masyarakat memahami keduanya merupakan pemberian properti pada pernikahan. ${ }^{9}$ Disisi lain praktek pembayaran mahar di Pakistan sama dengan model pembayaran mahar di negara India yaitu tradisi keluarga pengantin wanita membayar mahar kepada keluarga pengantin pria bersamaan dengan pemberian hadiah pernikahan. ${ }^{10}$ Praktek ini sangat berbeda

\footnotetext{
${ }^{5}$ Mudawanah al-Usroh 2016 Pasal 27

${ }^{6}$ Qonun al-Ahwal al-Syakhsiah 2011 Pasal 53

7 The Dowry And Bridal Gift (Restriction) Act, 1976 No. 2 sub section a.

8 The Dowry And Bridal Gift (Restriction) Act, 1976 No. 2 sub section b.

9 Momoe Makino, "Marriaage, Dowry, And Women's Status In Rural Punjab, Pakistan", Jurnal Popul Econ, Vol. 32 (Juli, 2018), 769.

10 AGEHI Resoutce Cenytr SACHET Pakistan, Dowry: A socially endorsed form of
} 
sekali dengan konsep mahar dalam Islam, yang mana secara aklamatif jumhur fukaha menyepakati mahar wajib diberikan suami kepada isterinya, hal ini berdasarkan teks alQur'an surat an-Nisa (4) ayat 4 serta Hadis Rasulullah saw. ${ }^{11}$

Prakter mahar yang berlangsung di negara Pakistan menimbulkan problematika sosial yang mana pihak wanita yang menjadi korban kekejaman sistem mahar ini. ${ }^{12}$ Sehingga banyak pihak menuntut penghapusan sistem mahar di negara Pakistan. Akhirnya peraturan besaran mahar di Pakistan di sahkan pada 4 Juni 1976 yang memuat 11 pasal oleh parlemen Pakistan.

Sebagai bahan untuk melakukan novelty, penulis mengkaji beberapa literatur yang memiliki pembahasan serumpun. Pertama, artikel yang berakar dari M. Atho' Mundzar tentang Hukum Keluarga Islam di negara Pakistan. Beliau berpendapat bahwasanya dalam menggagas materi hukum keluarga sangatlah sulit karena sengitnya perdebatan kaum konservatif dan modernis. Pemahaman ini dipengaruhi oleh sosial budaya yang telah mendarah daging di Pakistan. M. Athor Mundzar juga menilai bahwa undang-undang hukum keluarga di Pakistan di tinjau dari segi materinya berbanding vertikal dengan kitab fikih klasik, tetapi juga berbanding horizontal karena mendorong upaya meningkatkan status sosial wanita. ${ }^{13}$

violence in Pakistan, http://sachet.org.pk/wpcontent/uploads/2016/06/Forgotten-Research-Reporton-Dowry-Violence-in-Pakistan.pdf, diakses pada tanggal 14 Juni 2021.

${ }^{11}$ Noryamin Aini, "Tradisi Mahar Di Ranah Lokalitas Umat Islam: Mahar Dan Struktur Sosial Di Masyarakat Muslim Indonesia”, Jurnal Ahkam, Vol. VIX, No. 1, (Januari, 2014), 210.

12 Shazia Gulzar, Dkk, "Dowry System In Pakistan" Jurnal Asian Economic and Financial Review, Vol.2, No. 7 (Mei, 2014), 785.

${ }^{13}$ M. Atho Mudzar, "Hukum Keluarga di Pakistan (Antara Islamisasi dan Tekanan Adat)",
Kedua, artikel yang mengupas jumlah mahar di negara Muslim. Hasil dari artikel tersebut adalah bahwa ketentuan mahar di negara Yordania, Maroko, Syria, Indonesia, dan Pakistan memiliki aturan mahar yang jelas dan rinci. Hanya saja negara Pakistan sevara tegas membyar peraturan pembatasan jumlah besaran mahar serta sanksi bagi pihak yang melanggar. ${ }^{14}$

Berangkat dari adanya aturan mahar di negara pakistan, peneliti hendak meneliti lebih lanjut mengenai argumentasi dan tujuan adanya peraturan besaran mahar dalam UU Mahar 1976 negara Pakistan. Artikel ini menempatkan fokus kajian terhadap studi peraturan mahar di negara Pakistan. Pembahasan tulisan ini meliputi konsep mahar dan struktur sosial pakistan, argumentasi adanya peraturan, aturan mahar, serta tujuan peraturan mahar di Pakistan.

\section{B. Metode Penelitian}

Metode yang dipakai daam tulisan ini adalah metode kepustakaan atau yang lebih sering dikenal dengan istilah library research. Cara kinerja metode ini adalah dengan memaparkan data-data yang diperoleh melalui literatur-literatur yang memiliki keterkaitan dengan tema yang diteliti seperti buku, artikel, dokumen, jurnal, serta karya ilmiah lainya. Kemudian pendekatan yang dipakai oleh penulis adalah pendekatan deskriptif-analisis. Pendekatan ini berusaha menggambarkan atuan mahara 1976 pakistan, juga menganalisis dasar dan tujuan positifisasi peraturan tersebut.

\section{Pembahasan \\ 1. Konsep Mahar Dan Struktul Sosial Pakistan}

\footnotetext{
Jurnal al-'Adalah, Vol. XII, No.1 (Juni, 2014), 11 24.

${ }^{14}$ Qodariah Barkah, "Kedudukan dan Jumlah Mahar Di Negara Muslim”, Jurnal Ahkam, 279-286
} 
Mahar merupakan syarat sah perkawinan, sebab itu pemberian mahar merupakan suatu entitas yang wajib ada dalam pernikahan. Dalam Islam mahar merupakan pemberian wajib yang diserahkan laki-laki kepada calon pengantin peempuan. ${ }^{15}$ Hal ini berlandaskan al-Qur' an surat an-Nisa' (4) ayat 4 serta hadis-hadis Rasulullah saw. Mengenai sejarah pemberlakuan mahar dalam Islam, tidak terlepas dari pembahasan mahar di era jahiliyyah yang menganggap wanita sebagai second women. Pada kasus mahar perempuan sama sekali tidak memiliki hak untuk menggunakan dan memanfaatkan mahar yang diberikan oleh calon suaminya. Akan tetapi hak kepemilikian mahar sepenuhnya dipegang oleh walinya sebagai imbalan yang diberlakukan sebagai ganti rugi perawatan. Lalu Islam datang untuk melepaskan belenggu ini dari perempuan, dan menjadikan mahar menjadi hak atasnya, sedangkan walinya juga tidak boleh mengambil mahar darinya kecuali memperoleh izin dan ridho dari anak perempuanya. $^{16}$

Secara historis mahar mempunyai benang merah dengan berbagai variabel, misalnya variabel sosial, budaya, dan ekonomi. Fakta ini tersinggung dalam dinamika perkembangan kehidupan masyarakat. Adanya benang merah (titik singgung) ini dapat dilacak dengan adanya sejarah di pra Islam dan juga berbagai perbedaaan transliterasi istilah mahar (mahr: Arab) pada ranah lokalitas seperti dowry (inggris), maskawin (Jawa), uang panaik (Makasar), jujuran (Banjar), mahar, serta pisuka dan ajikrama (Sasak), yang

15 Amir Syarifuddin, Hukum Perkawinan Islam di Indonesia, (Jakarta: Kencana, 2011), 85.

${ }^{16}$ Sayyid Sabiq, Fiqih Sunnah Jilid 3", Terj. Abu Syauqina, (Jakarta: Tinta Abadi Gemilang, 2013), 412. mengindikasikan adanya bermacam-macam konseptualisasi dan pemahaman. ${ }^{17}$

Secara kajian sosial juga mahar merupakan suatu praktek yang erat kaitanya dengan struktural masyarakat tertentu. Pada masyarakat tertentu mahar diekspresikan ke dalam kelas sosial suatu keluarga, terlebih yang terjadi pada masyarakat Pakistan yang bertipe patrilineal. Masyarakat ini menjadikan pihak keluarga laki-laki sebagai tolak ukur tinggi rendahnya status sosial. Oleh karena itu, banyak keluarga yang notabenya adalah kelas menengah kebawah berhasrat untuk menikahkan anak perempuanya dengan laki-laki yang berstatus sosial tinggi, tujuanya tidak lain adalah demi kebutuhan mobilitas sosial. Pemahaman ini berakibat pada praktek mahar di negara Pakistan yang tidak relevan dengan konsepsi mahar dalam Islam, yaitu pihak keluarga perempuan yang memberikan mahar kepada suami dengan tujuan untuk memperoleh kasta dan status sosial yang lebih tinggi. Tradisi ini ternyata tidak hanya berlaku di Pakistan, melainkan juga negara bagian Asia Selatan seperti, India, dan Bangladesh. ${ }^{18}$

Pada masyarakat Pakistan juga, mahar dijadikan sebagai asuransi dan nilai ekonomis utuk jaminan perempuan dimasa depan. Disamping ingin memperoleh status sosial yang tinggi juga sebagai dimensi investasi, meskipun pada prakteknya mahar di Pakistan belum bisa memberi jaminan ekonomi bagi perempuan. ${ }^{19}$ Padahal dalam

${ }^{17}$ Noryamin Aini, "Tradisi Mahar Di Ranah Lokalitas Umat Islam: Mahar Dan Struktur Sosial Di Masyarakat Muslim Indonesia”, 14

18 Rao, 'Dowry Inflation' in Rural India: A Statistical Investigation," Population Studies, Vol. 47 (2), (1993), . 283-293; Nishimura, "Marriage Payments among the Nagarattars in South India," Contributions to Indian Sociology, Vol. 28 (3), (1994), 243-272.

19 AGEHI Resoutce Cenytr SACHET Pakistan, Dowry: A socially endorsed form of 
konsep Islam tidak terlalu menekankan pada nilai ekonomis, melainkan Islam menekankan filosofi mahar sebagai simbol keseriusan, ketulusan cinta dan kasih sayang. ${ }^{20}$

Praktek mahar di Pakistan yang memproyeksikan nilai mahar yang tinggi dan status sosial yang lebih rendah membuat perempuan sering mengalami berbagai macam kekerasan fisik maupun psikis, bahkan penyiksaan tersebut mengatas namakan tradisi. ${ }^{21}$ Kekerasan fisik disebabkan karena istri ingin segera menceraikan suaminya, sedangkan pihak suami enggan untuk menceraikanya dengan dalih tidak ingin uang mahar kembali ke tangan istri. Sedangkan kekerasan psikis disebabkan oleh ketidakpuasan mertua terhadap jumlah mahar yang diserahkan oleh pihak perempuan, juga perempuan tidak mempunyai kendali atas pemanfaatan mahar yang membuat perempuan memilih untuk bunuh diri. ${ }^{22}$

Mahar yang menjadi fenomena umum yang mengakar di Pakistan dianggap tidak Islami dan keluar dari norma agama, karena syariat Islam tidak membebankan biaya apapun kepada orang tua mempelai perempuan. Utamanya mahar ditanggung pihak laki-laki, kemudian mahar diserahkan ke calon mempelai perempuan. Oleh karena itulah banyak masyarakat yang menganggap

violence in Pakistan, http://sachet.org.pk/wpcontent/uploads/2016/06/Forgotten-Research-Reporton-Dowry-Violence-in-Pakistan.pdf, diakses pada tanggal 14 Juni 2021, 13.

${ }^{20}$ Khoiruddin Nasution, Islam Tentang Relasi Suami dan Isti (Hukum Perkawinan 1), 168.

${ }^{21}$ Tazeen Saeed Ali, Gunnhildur Arnadottir, and Asli Kulane, "Dowry Practices and Their Negative Consequensces From a Female Perspective in Karachi, Pakistan a Qualitative Study", Journal Health, Vol. 5, No. 7A4, (Juli, 2013), 88.

${ }^{22}$ Tazeen Saeed Ali, Gunnhildur Arnadottir, and Asli Kulane, "Dowry Practices and Their Negative Consequensces From a Female Perspective in Karachi, Pakistan a Qualitative Study", 88. bahwa sistem mahar di Pakistan merupakan kezaliman dan kejahatan sosial. ${ }^{23}$

\section{Argumentasi Lahirnya UU Mahar 1976 Pakistan.}

Secara historis supremasi hukum di Pakistan sampai 14 Agustus 1947 masih ikut kepada negara India. Untuk lebih lengkapnya runtutan historis terbentuknya Undang-Undang Hukum Keluarga Pakistan, sebagai berikut; ${ }^{24}$

1) Peraturan Pembubaran Pernikahan 1869,

2) Peraturan Perkawinan Kristen 1872 ,

3) Peraturan Perwalian 1890,

4) Peraturan Validasi Wakaf 19131930 ,

5) Peraturan Wakaf 1923 (diamandemen di Propinsi Sind oleh UU lokal, yakni UU No.18/1935),

6) Peraturan Disposisi Properti Hindu 1916,

7) Peraturan Amandemen Hukum Warisan 1929,

8) Peraturan Larangan Pernikahan Anak 1929,

9) Peraturan Pengesahan Pengesahan Pernikahan Arya 1937, dan

10) Peraturan Pembubaran Pernikahan Muslim 1939.

Kemudian di tahun 1961. Komisi Nasional negara Pakistan merekomendasikan beragam masalah keluarga untuk penyempurnaan Undangundang Hukum Keluarga yang ada. Atas dasar rekomendasi yang dibuat Komisi

23 Sanchita Bhattacharya, "Status women in Pakistan", J.R.S.P., Vol. 51, No. 1, (Januari-Juni: 2014), 190.

${ }^{24}$ Tahir Mahmood, Personal Law In Islamic Cauntries (history, text and comparative analisys), (New Delhi, Academy Of Law And Religion, 1987), 59. 
tersebut, suatu ketetapan yang dikenal sebagai Muslim Family Law Ordinance (MFLO) yang disahkan pada tahun 1961. Pasca kelahiran UU tersebut, ada beberapa peraturan yang kaitanya membahas family law seperti; UU Mahar dan Hadiah Tahun 1976, dan UU Larangan Pemborosan Tahun 2000 yang diamandemen pada tahun 2003.

Mengenai selanjutnya menjadi UU Mahar 1976 terdapat dua argumentasi penting yang menimbulkan lahirnya peraturan tersebut, yaitu; perbedaan pemahaman konsep mahar dan praktek mahar yang menimbulkan problem sosial.

1) Perbedaan pemahaman konsep mahar.

Seperti yang telah diuraikan bahwa konsep mahar di Pakistan sangat berbeda dengan konsep menurut agama Islam yang termaktub dalam al-Qur'an dan Sunnah, pemahaman mahar di Pakistan murni karena adanya asimilasi budaya hindu india yang mentipologikan kasta-kasta sosial. Konsep mahar dalam Islam tidak membebankan biaya apapun kepada orang tua mempelai wanita, bahkan biaya pernikahan, dianjurkan, harus ditanggung oleh mempelai laki-laki. $^{25}$

Disisi lain, kata dowry yang berarti mas kawin/mahar adalah kata ambigu yang tidak memiliki standar definisi yang pasti, serta ada terdapat variasi dalam pemahaman mengenai dowry. Definisi secara umum memang dowry merupakan hadiah dan aset berharga. Menurut Sylvia Vatuk, dowry mempunyai kesamaan (similar) dengan kata dahej atau dan dahej di India yang memiliki arti 'serangkaian hadiah yang diberikan oleh rumah tangga atau keluarga besar pengantin. Kemudian dowry (mas kawin) dan dahej

25 AGEHI Resoutce Cenytr SACHET Pakistan, Dowry: A socially endorsed form of violence in Pakistan, http://sachet.org.pk/wpcontent/uploads/2016/06/Forgotten-Research-Reporton-Dowry-Violence-in-Pakistan.pdf, diakses pada tanggal 14 Juni 2021, 23. dikontraskan dengan hadiah yang diberikan kepada pengantin wanita oleh pengantin pria untuk pakaiannya. ${ }^{26}$

Pemahaman mahar di Pakistan dinilai rancu, karena banyak sekali pemberian dalam adat perkawinan di Pakistan, seperti; 1). Bridal gift, merupakan pemberian yang dijanjikan pada calon mempelai perempuan dari pihak mempelai laki-laki saat/setelah akad nikah, tetapi bukan terhitung sebagai mahar, 2). Present merupakan pemberian hadiah yang diperuntukan kepada keluarga pengantin laki-laki atau perempuan yang kaitanya dengan adanya suatu pernikahan. ${ }^{27}$ Hal ini mengundang pemahaman bahwa segala sesuatu pemberian dianggap sebagai mahar.

Menurut U.H Ghori bahwa mahar (dowry) yang dipraktikan oleh masyarakat Muslim benua asia selatan (India, Pakistan, Bangladesh) terbangun oleh budaya varâdhakshina yang diikuti oleh orangorang Hindu yang cenderung hedonistik dan konsumerisme. ${ }^{28}$ Dalam tradisi masyarakat Hindu di India, mahar (varâdhakshina) lebih diproyeksikan sebagai pemberian hadiah kepada mempelai pria dan tumbuh sebagai tradisi didalam kasta brahma. Kemudian pada paruh abad ke-20 tradisi pembayaran mahar kepada mempelai pria juga menjadi tren di kalangan agama lain, tidak terkecuali Islam. $^{29}$

2) Praktek mahar menimbulkan problem sosial.

${ }^{26}$ Abdullah Waheed, "Dowry Among Indian Musims: Ideals and Practices", Indian Journal of Gender Studies, Vol. 16, No. 1, (2009), 49.

27 M. Atho Mudzar, "Hukum Keluarga di Pakistan (Antara Islamisasi dan Tekanan Adat)", Jurnal al-‘Adalah, Vol. XII, No.1 (Juni, 2014), 18.

28 Abdullah Waheed, "Dowry Among Indian Musims: Ideals and Practices", . 55

29 N. Ashraf, "Dowry among Muslims in Bihar", Economic and Political Weekly, Vol. 32, No. 52, (Desember -Januari 1998), 3310 
Beberapa organisasi perempuan yang menangani isu-isu terkait kekerasan terhadap perempuan memberikan dukungan kepada perempuan yang menjadi korban kekerasan. Mereka mengkategorikan mahar di Pakistan sebagai budaya yang meresahkan dan mengecewakan. Pada tahun 1960-1970 terjadi kampanye yang tujuanya menyadarkan masyarakat dan memberikan pencerahan bahwa sistem mahar yang terjadi di masyarakat telah menjadikan mahar seagai problem yang mendiskriditkan perempuan.Upaya ini juga didukung dengan penolakan tuntutan mahar yang dinilai tidak masuk akal. ${ }^{30}$

Problem sosial yang terjadi di Pakistan adalah sikap yang mendiskriminasi pihak perempuan, karena masih menganggap perempuan sebagai kalangan kasta kedua setelah laki-laki. Kekerasan yang terjadi dalam rumah tangga yang tidak hanya dilakukan oleh para suami saja, melaikan juga mertua yang sering sekali melecehkan menantuya sendiri karena kurang mampu membayar mahar yang telah disepakati. $^{31}$

Sistem mahar yang berlangsung di negara Pakistan merupakan beban bagi keluarga, dan tekanan mahar terkadang mendorong keluarga untuk mengambil pinjaman untuk memenuhi kewajibannya. Orang tua memberikan mahar kepada anak perempuan mereka sesuai dengan kemampuan mereka, tetapi terkadang anak perempuan dalam keluarga miskin tetap

30 AGEHI Resoutce Cenytr SACHET Pakistan, Dowry: A socially endorsed form of violence in Pakistan, http://sachet.org.pk/wpcontent/uploads/2016/06/Forgotten-Research-Reporton-Dowry-Violence-in-Pakistan.pdf, diakses pada tanggal 14 Juni 2021, 21.

31 Tazeen Saeed Ali, Gunnhildur Arnadottir, and Asli Kulane, "Dowry Practices and Their Negative Consequensces From a Female Perspective in Karachi, Pakistan a Qualitative Study", 88. tidak menikah karena ketidakmampuan orang tua untuk memberikan mahar. ${ }^{32}$

Lebih lanjut orang tua atau saudara sendiri tidak mampu memenuhi mata pencaharian untuk keluarga karena nilai ekonomi mereka yang sangat rendah, sehingga biaya mas kawin tambahan menghancurkan ekonomi rumah mereka. Apabila orang tua tidak dapat memenuhi tuntutan itu, itu mungkin memiliki konsekuensi negatif bagi putri mereka. Banyak kasus juga penelantaran anak perempuan karena dianggap beban perekonomian dan ketidakmampuan wali untuk membayar mahar. Setidaknya terdapat lima konsekuensi negatif dari praktek mahar di Pakistan, yaitu; perceraian, kekerasan, istri tidak mendapatkan kemanfaatan mahar, kematian akibat sistem mahar, dan mahar menjadi sumber perbandingan. ${ }^{33}$

Sedangkan Shazia Gulzar mengemukakan dampak kerugian yang timbul akibat budaya mahar, yaitu: ${ }^{34}$

1) Keluarga yang sangat miskin ketika menuntut mas kawin untuk anak perempuanya saat menikah melibatkan diri dalam memohon dan mengemis, tidak peduli dengan harga dirinya lagi.

2) Wanita menjadi terpengaruh secara mental karena mereka tidak dapat memenuhi jumlah mas kawin dan mereka terus disiksa oleh mertuanya.

${ }^{32}$ Tazeen Saeed Ali, Gunnhildur Arnadottir, and Asli Kulane, "Dowry Practices and Their Negative Consequensces From a Female Perspective in Karachi, Pakistan a Qualitative Study”, 88

${ }^{33}$ Tazeen Saeed Ali, Gunnhildur Arnadottir, and Asli Kulane, "Dowry Practices and Their Negative Consequensces From a Female Perspective in Karachi, Pakistan a Qualitative Study”, 88.

34 Shazia Gulzar, Dkk, "Dowry System In Pakistan" Jurnal Asian Economic and Financial Review, Vol. 2, No. 7 (Mei, 2014), 785. 
3) Karena sistem mas kawin, orang miskin tidak menikahi anak perempuanya. Selain itu, usianya sedikit demi sedikit terkikis dan mengalami depresi karena tidak bisa menikah. Pada akhirnya banyak kejadian perempuan yang bunuh diri.

4) Untuk memenuhi permintaan mas kawin beberapa gadis keluarga kelas bawah mencoba untuk mendapatkan uang dari cara yang jahat dan tidak etis.

Pengesahan sosial budaya dan adat mahar yang ditunjukkan dengan penerimaan mahar sebagai norma menjadi problem serius yang harus dientaskan bersama. Mahar dan kekerasan melibatkan. Oleh karena itu semua kementerian terkait bekerja sama untuk memperkenalkan perubahan transformatif yang secara langsung akan memperbaiki kondisi dan posisi kaum perempuan di Pakistan, juga menentang tren patriarki masyarakat. Dengan demikian peraturan mahar yang tercantum dalam UU Mahar 1976 disahkan di parlemen pada 4 juli $1976 .{ }^{35}$

\section{Aturan Mahar dalam UU Mahar 1976}

Pada peraturan ini, terdapat macammacam definitif yang berkaitan dengan pemberian hadiah dalam perkawinan yang meliputi Bridal gift, yaitu merupakan pemberian yang dijanjikan kepada calon mempelai perempuan oleh pihak mempelai laki-laki ketika/setelah akad perkawinan, hanyasaja bukan termasuk mahar. ${ }^{36}$ Lalu

35 AGEHI Resoutce Cenytr SACHET Pakistan, Dowry: A socially endorsed form of violence in Pakistan, http://sachet.org.pk/wpcontent/uploads/2016/06/Forgotten-Research-Reporton-Dowry-Violence-in-Pakistan.pdf, diakses pada tanggal 14 Juni 2021, 20.

36 The Dowry And Bridal Gift (Restriction) Act, 1976 No. 2 sub section a. dowry yang berarti segala harta benda yang diberikan sebelum, pada atau setelah perkawinan baik secara langsung maupun tidak langsung, kepada mempelai wanita oleh orang tuanya sehubungan dengan perkawinan tetapi tidak termasuk harta yang dapat diwarisi oleh mempelai wanita berdasarkan hukum waris. $^{37}$ Sedangkan present merupakan pemberian hadiah yang diperuntukan kepada keluarga pengantin laki-laki atau perempuan yang kaitanya dengan suatu pernikahan tetapi tidak termasuk neundra dan salami. ${ }^{38}$

Peraturan mahar di Pakistan sejak awal disinggung agar terdapat perincian besaran mahar dalam pernikahan. Jika tidak ada rincian pembayaran mahar maka seluruh jumlah mahar akan ditentukan sesuai dengan permintaan. Hal ini tertuang dalam MLFO 1961 Pakistan ayat 10 yang menyatakan "Where no details about the mode of payment of dower are specified in the nikah nama, or the marriage contract, the entire amount of the dower shall be prescribed to be payable on demand". 39

Namun pada peraturan UU Mahar 1976 terdapat batasan mengenai besaran mahar di negara Pakistan, yaitu nilai keseluruhan mahar dan hadiah tidak boleh melebihi 5.000 Rs. Hal ini disebutkan dalam pasal 3 ayat 1 yang berbunyi: (1) Neither the aggregate value of the dowry and presents given to the bride by her parents nor the aggregate value of the bridal gifts or of the presents given to the bridegroom shall exceed five thousand rupees. ${ }^{40}$

37 The Dowry And Bridal Gift (Restriction) Act, 1976 No. 2 sub section b.

${ }^{38}$ The Dowry And Bridal Gift (Restriction) Act, 1976 No. 2 sub section e.

${ }^{39}$ The Muslim Family Laws Ordinance, 1961 pasal 10 .

${ }^{40}$ The Dowry And Bridal Gift (Restriction) Act, 1976 No. 3 Ayat 1. 
Pada pasal 3 ayat 2 disebutkan bahwasanya mahar, kado atau hadiah perkawinan tidak boleh diberikan sebelum atau setelah enam bulan nikah. ${ }^{41}$ Pada kasus pemberian present juga terdapat batasan yaitu boleh memberikan kepada salah satu pihak dalam perkawinan hadiah apa pun yang nilainya melebihi 100 Rs, tetapi nominal ini tidak berlaku untuk present yang diberikan kepada mempelai laki-laki oleh orang tua mempelai wanita. Hal ini tertera dalam pasal 4 yang berbunyi; (4) No person shall give to either party to the marriage any present the value of which exceeds one hundred rupees: Provided that the limit of one hundred rupees shall not apply to the presents given to the bridegroom by the parents of the bride. ${ }^{42}$

Pada peraturan ini terdapat penegasan yang menjadi poin utama yaitu segala macam properti atau pemberian sebagai mahar diberikan kepada pengantun perempuan secara mutlak. Penyataan ini terdapat pada pasal 5 yang berbunyi; (5) All property given as dowry or bridal gifts and all property given to the bride as a present shall vest absolutely in the bride and her interest in property however derived shall hereafter not be restrictive, conditional or limited. ${ }^{43}$

Selanjutanya pada pasal 7 dipaparkan bahwa orang tua masing-masing pihak wajib memperlihatkan semua mahar, pemberian, serta hadiah yang diberikan dan diterima agar dapat dilihat oleh semua orang. $^{44}$ Kemudian mahar maupun pemberian hadiah tersebut harus didaftarkan

41 The Dowry And Bridal Gift (Restriction) Act, 1976 No. 3 Ayat 2.

${ }^{42}$ The Dowry And Bridal Gift (Restriction) Act, 1976 No. 4.

${ }^{43}$ The Dowry And Bridal Gift (Restriction) Act, 1976 No. 4.

${ }^{44}$ The Dowry And Bridal Gift (Restriction) Act, 1976 No. 7. kepada panitera beserta rincian besaran nilai dan ditandantangi oleh orang yang menyerahkan kepada panita dan dibuktikan oleh dua orang saksi. Tentang waktu pemberian rincian kepada panitera adalah satu minggu. ${ }^{45}$

Konsekuensi apabila tidak mematuhi ataupun melanggar UU Mahar 1976 yaitu akan dihukum penjara dengan jangka waktu yang dapat diperpanjang hingga enam bulan, atau dengan denda yang dapat diperpanjang hingga sepuluh $10.000 \mathrm{Rs}$, atau bisa saja dihukum denda dan penjara. Kemudian mahar, hadiah (bridal gift) atau hadiah pengantin (presents given) bertentangan dengan ketentuan Undang-undang ini, maka akan diserahkan kepada federal untuk digunakan pada acara pernikahan masyarakat miskin dengan cara yang ditentukan. ${ }^{46}$

\section{Manifestasi Reformasi serta Tujuan Aturan Mahar di Pakistan}

Dapat dikatakan bahwa adanya pembaharuan hukum keluarga Islam dimana mahar merupakan salah satu bagiannya merupakan sebuah keniscayaan. ${ }^{47}$ Adapun manifestasi reformasi yang dimaksud adalah postivisasi-Islamisi kedalam UndangUndang. Setidaknya terdapat hal tujuan pembaharuan perundang-undangan, yaitu: ${ }^{48}$

1) Untuk memberikan kepastian hukum, khususnya berkenaan dengan masalah perkawinan. Karena sebelum adanya peraturan yang legal,

45 The Dowry And Bridal Gift (Restriction) Act, 1976 No. 8.

46 The Dowry And Bridal Gift (Restriction) Act, 1976 No. 9.

${ }^{47}$ Qodariah Barkah, "Kedudukan dan Jumlah Mahar Di Negara Muslim”, 279.

48 Khoiruddin Nasution, Hukum Perdata (Keluarga) Islam Indonesia dan Perbandingan Hukum Perkawinan di Dunia Muslim, (Yogyakarta: ACAdeMIA\&Tazzafa, 2013), 40 
aturan perkawinan hanya bersifat judge made law.

2) Mengangkat status wanita serta melindungi hak-hak wanita, sehingga sesuai harapan dan citacita.

3) Untuk menciptakan peraturan yang relevan dengan konteks perkembangan zaman.

Ketiga tujuan adanya pembaharuan Undang-Undang setidaknya relevan dengan adaya tujuan peraturan mahar di Pakistan. Pertama, adanya jaminan kepastian hukum berarti adanya polariasi terhadap ketentuan mahar, pola yang dibangun pertama kali adalah pemberian kepastian definisi pemberian dalam kontek perkawinan yang meliputi dowry, bridal gift, dan present yang sangat rancu dan sulit dipahami oleh masyaratakat Pakistan, mengingat argumentasi lahirnya peraturan ini adalah terdapat perbedaan pemahaman mengenai konsep mahar, yaitu diserahkan oleh keluarga perempuan kepada pihak suami untuk memperoleh kasta sosial yang tinggi. Dengan adanya UU Mahar 1976 menekankan pemahaman bahwa hanya pemberian present yang membolehkan pihak istri memberikan hadiah ke suami, berbeda dengan mahar (dowry).

Selanjutnya adalah serta kepastian hukum dalam prakter dan besaran mahar, hal ini kaitanya dengan praktek kelam sistem mahar di Pakistan yang sangat tinggi, sehingga memberatkan pihak perempuan dalam memberikan mahar kepada pihak laki-laki. Hadirnya peraturan mahar ini merekontruksi praktek mahar yang tidak relevan dengan Islam serta mereduksi nominal yaitu hanya sebesar 5.000 Rs. Hal ini dinilai adil karena tidak akan lagi tradisi mahar yang menjadi problem-problem sosial.
Kemudian agar peraturan tersebut dapat terealisi dengan baik maka mahar harus dan pemberian dalam pernikahan harus didaftarkan ke panitera secara rinci, serta terdapat saksi dalam proses pendaftaran. Hal ini dilakukan agar tidak terjadi penyelewengan praktek mahar dan besaran mahar. Adapun konsekuensi apabila terjadi pelanggaran terhadap aturan mahar adalah seseorang tersebut akan dikenai sanksi yang berupa penjara dan denda agar tercipta efek jera bagi orang-orang yang tidak mentaati peraturan tersebut.

Kedua, aturan mahar juga merupakan wujud penghargaan bagi kaum perempuan yang hak-haknya dirampas akibat tradisi mahar yang tidak sehat. Secara ekspisit aturan mahar mengembalikan fitrah perempuan sebagai manusia kelas atas yang tidak ada kaitanya dengan strata sosial. Tidak ada lagi kekerasan fisik ataupun psikis yang mengakibatkan diskriminasi terhadap keluarga perempuan. Adanya konsep pemberian mahar dilakukan oleh calon memepelai suami kepada bakal istri yang relevan dengan konsep Islam, mengidikasikan adanya penghormatan sejati sebagai cinta yang aktual, bukan berdasarkan pembelian status sosial. Di samping itu, adanya kepemilikan mahar secara mutlak oleh istri dinilai dalam rangka mewujudkan penghargaan kepada kaum perempuan. Artinya mahar tidak milik walinya dan perempuan bebas memanfaatkan maharnya untuk kepentingan kehidupan.

Ketiga, aturan mahar dinilai dalam rangka menyesuaikan dengan konteks perkembangan zaman. Maksudnya kondisi kekinian dalam sebuah negara dapat menjadi pertimbangan dalam melahirkan aturan tentang mahar. Hal ini terlihat dari adanya rekontruksi terhadap praktek mahar yang dinilai tidak sesuai dengan ajaran syariat 
Islam. Dengan demikian prakterk mahar kembali kepada filosofi awal yaitu sebagai bentuk penghormatan terhadap kaum wanita.

Disi lain, perkembangan zaman menuntut pengapusan segala macam bentuk diskriminasi terhadap jenis kelamin, suku, ras, dan agama. Tidak hanya itu, sikap egaliter pria dan wanita merupakan tuntutan bagi setiap supremasi hukum demi terwujudnya kemaslahatan. Aplikasinya dalam mahar misalnya, adanya mahar dalam perkawinan merupakan salah satu bentuk keseriusan calon mempelai pria pada wanita pilihannya, selanjutnya mahar yang telah diberikan ialah murni menjadi milik istri. Kaitanya dengan ketentuan besaran mahar yang harus ditunaikan, tergantung dasar kesepakatan antar kedua belah pihak, asalkan tidak memberatkan bagi pihak suami. $^{49}$

Sejatinya, bahwa manifestasi dari tujuan adanya peraturan mahar adalah sebagai positivisasi-Islamisasi perundangundangan, mengingat bentuk dari negara Pakistan adalah republik Islam. Selain itu, adanya peraturan mahar termasuk upaya untuk menciptakan hukum yang egaliter, yaitu hukum dengan menyetarakan hak dan perempuan pria dan wanita. ${ }^{50}$

Adapun secara keseluruhan, manifetasi reformasi adanya ketentuan mahar di pakistan sebagai positivasi syariat Islam, hal ini bisa dilacak dalam konstitusi negara Pakistan tahun 1974 yang menyatakan keseluruhan undang-undang harus disesuaikan dengan ajaran dan nlainilai Islam, serta tidak boleh seluruh

${ }^{49}$ Hulaimi Azhari, "Pembaruan Islam Bidang Hukum Keluarga dan Relevansinya dengan Tuntuan Egaliter Pria dan Wanita", JPA, Vol. 21, No. 2, (JuliDesember, 2020), 185.

50 Departemen Pendidikan dan Kebudayaan, Kamus Besar Bahasa Indonesia, (Kantor Balai Pustaka, Jakarta, 1989), 285. peraturan kontradiktif dengan ajaran agama Islam. Sebab itu, pasca konstirusi 1974 pemerintahan Pakistan memutuskan menegakan supremasi syariah di segala aspek di bidang hukum. ${ }^{51}$

\section{Kesimpulan}

Paparan mengenai studi peraturan mahar di Pakistan sebagaimana yang telah diuraikan dalam artikel ini, yaitu; Pertama, terdapat dua argumentasi penting yang menimbulkan penetapan peraturan tersebut, yaitu; a) perbedaan pemahaman konsep mahar yang berbeda dengan Islam, dimana pemahaman mahar di Pakistan murni karena adanya asimilasi budaya hindu india yang mentipologikan kasta-kasta sosial, sehingga mahar dibebankan kepada pihak perempuan. b). Praktek mahar menimbulkan problem sosial, akibat dari pemahaman mahar yang keliru menimbulkan praktek mahar yang keliru juga, sehingga problem sosial salah satunya berakar dari sistem mahar. Kedua, bahwasanya manifestasi dari tujuan adanya peraturan mahar di Pakistan adalah rekonstruksi prakter mahar melalui penetapan UU Mahar 1976. Undang-undang ini relevan dengan tujuan pembaharuan hukum keluarga Islam, yaitu; a). Untuk memberikan kepastian hukum, khususnya berkenaan dengan masalah perkawinan, khususnya mahar. b). turan mahar juga merupakan wujud penghargaan bagi kaum perempuan yang hak-haknya dirampas akibat tradisi mahar yang tidak sehat. c). Aturan mahar dinilai dalam rangka menyesuaikan dengan konteks perkembangan zaman, yaitu tuntutan egaliter.
${ }^{51}$ Rohmadi, "Syari;ah dan Politik Hukum Keluarga di Negara Pakistan". Jurnal al-Mizan, Vol. 1, No. 2, (2014), 22. 


\section{Daftar Pustaka}

AGEHI Resoutce Cenytr SACHET Pakistan, Dowry: A socially endorsed form of violence in Pakistan, http://sachet.org.pk/wpcontent/uploads/2016/06/ForgottenResearch-Report-on-DowryViolence-in-Pakistan.pdf, diakses pada tanggal 14 Juni 2021

Aini, Noryamin. “Tradisi Mahar Di Ranah Lokalitas Umat Islam: Mahar Dan Struktur Sosial Di Masyarakat Muslim Indonesia", Jurnal Ahkam, Vol. VIX, No. 1, (Januari, 2014)

Ali, Tazeen Saeed, Gunnhildur Arnadottir, and Asli Kulane, "Dowry Practices and Their Negative Consequensces From a Female Perspective in Karachi, Pakistan a Qualitative Study", Journal Health, Vol. 5, No. 7A4, (Juli, 2013)

Ashraf, N. "Dowry among Muslims in Bihar", Economic and Political Weekly, Vol. 32, No. 52, (Desember -Januari 1998), hlm. 3310-3320

Azhari, Hulaimi, "Pembaruan Islam Bidang Hukum Keluarga dan Relevansinya dengan Tuntuan Egaliter Pria dan Wanita", JPA, Vol. 21, No. 2, (JuliDesember, 2020), hlm, 173-187.

Barkah, Qodariah. "Kedudukan dan Jumlah Mahar Di Negara Muslim", Jurnal Ahkam, Vol. XIV, No. 2, (Juli, 2014), hlm. 278-286

Departemen Pendidikan dan Kebudayaan, Kamus Besar Bahasa Indonesia, (Kantor Balai Pustaka, Jakarta, 1989)

Fatiyah, Atiqoh. "Studi Komparatif Kedudukan Mahar Pernikahan di Negara Indonesia dan Pakistan",
Skripsi UIN Syarif Hidayatullah Jakarta, (2016)

Huda, Ahmad Fatkhul. "Argumentasi dan Sanksi Atas Ketentuan Pembatasan Mahar Pernikahan (Studi Komperatif Hukum Keluarga Islam Indonesia dan Pakistan), Skripsi, Institut Agama Islam Negeri Ponorogo, (2019).

Inpres No, 1 Tahun 1991 Kompilasi Hukum Islam.

Mahmood, Tahir. Prsonal Law In Islamic Cauntries (history, text and comparative analisys) (New Delhi: Academy Of Law And Religion, 1987)

Makino, Momoe. "Marriaage, Dowry, And Women's Status In Rural Punjab, Pakistan", Jurnal Popul Econ, Vol. 32 (Juli, 2018)

Mudawanah al-Usroh 2016

Mudzar, M. Atho. "Hukum Keluarga di Pakistan (Antara Islamisasi dan Tekanan Adat)", Jurnal al'Adalah, Vol. XII, No.1 (Juni, 2014), hlm. 11-24

Nasution, Khoiruddin. Hukum Perdata (Keluarga) Islam Indonesia dan Perbandingan Hukum Perkawinan di Dunia Muslim, (Yogyakarta: ACAdeMIA\&Tazzafa, 2013)

Islam Tentang Relasi Suami dan Isti (Hukum Perkawinan 1), Cet I (Yogyakarta: ACAdeMIA \& TAZZAFA, 2004)

Nishimura, "Marriage Payments among the Nagarattars in South India," Contributions to Indian Sociology, Vol. 28 (3), (1994)

Qonun al-Ahwal al-Syakhsiah 2011 
Rao, "Dowry Inflation' in Rural India: A Statistical Investigation," Population Studies, Vol. 47 (2), (1993)

Rohmadi, "Syari'ah dan Politik Hukum Keluarga di Negara Pakistan". Jurnal alMizan , Vol. 1, No. 2, (2014), hlm. 18-26.

Sayyid Sabiq, Fiqih Sunnah Jilid 3", Terj. Abu Syauqina, (Jakarta: Tinta Abadi Gemilang, 2013)

Septyarany, Nisa. "Ketentuan Mahar Dalam Perkawinan (Studi Komparatif Hukum Keluarga Islam Yordania dan Pakistan), Skripsi, Institut Agama Islam Negeri Ponorogo, (2019).
Shazia Gulzar, Dkk, "Dowry System In Pakistan" Jurnal Asian Economic and Financial Review, Vol.2, No. 7 (Mei, 2014)

Syarifuddin, Amir. Hukum Perkawinan Islam di Indonesia, (Jakarta: Kencana, 2011)

The Dowry And Bridal Gift (Restriction) Act, 1976

Waheed, Abdullah, "Dowry Among Indian Musims: Ideals and Practices", Indian Journal of Gender Studies, Vol. 16, No. 1, (2009), hlm. 47-76. 